\title{
Disability, caregiver's dependency and patterns of access to rehabilitation care: results from a national representative study in Peru
}

\author{
Antonio Bernabe-Ortiz ${ }^{1,2}$, Francisco Diez-Canseco ${ }^{2}$, Alberto Vásquez ${ }^{3}$, and J. Jaime Miranda ${ }^{2,4}$ \\ ${ }^{1}$ Escuela de Medicina, Universidad Peruana de Ciencias Aplicadas, Lima, Peru, ${ }^{2}$ CRONICAS Center of Excellence in Chronic Diseases, Universidad \\ Peruana Cayetano Heredia, Lima, Peru, ${ }^{3}$ Sociedad y Discapacidad - SODIS, Lima, Peru, and ${ }^{4}$ Department of Medicine, School of Medicine, \\ Universidad Peruana Cayetano Heredia, Lima, Peru
}

\begin{abstract}
Purpose: To determine the prevalence of disability in Peru, explore dependency on caregiver's assistance and assess access to rehabilitation care. Method: Data from Disability National Survey (ENEDIS), including urban and rural areas, were analyzed. Disability was defined as a permanent limitation on movement, vision, communication, hearing, learning/remembering or social relationships. Dependency was defined as the self-reported need for a caregiver to help with daily activities; and access to rehabilitation care was defined as the self-report of any therapy for disabilities. Estimates and projections were calculated using sample strata, primary sampling units and population weights, and prevalence ratios (PRs) and $95 \% \mathrm{Cl}$ were reported. Results: From 798308 people screened, $37524(5.1 \%$; $95 \% \mathrm{Cl} 4.9-5.2 \%)$ had at least one disability. A total of 37117 were included in further analysis, mean age 57.8 (SD \pm 24.1$)$ years, $52.1 \%$ women. Dependency was self-reported by 14980 (40.5\%; 95\%Cl: 39.2-41.9\%) individuals with disabilities. A family member, usually female, was identified as a caregiver in $94.3 \%$ (95\%Cl: $93.3-95.3 \%)$ of dependent participants. Only $2881(10.7 \%$; $95 \% \mathrm{Cl}$ : $9.7-11.9 \%)$ of people with disabilities reported access to rehabilitation care. Major inequality patterns of disability burden versus access to rehabilitation care were observed by age and education level. Older age groups had higher disability burden yet lower chances of access to rehabilitation care. Conversely, the higher the education level, the lesser the overall disability burden but also the higher chances of reporting receiving care. Private healthcare insurance doubled the probability of having access to rehabilitation compared with those without insurance. Conclusions: Approximately 1.6 million Peruvians have at least one disability, and $40 \%$ of them require assistance with daily activities. Informal caregiving, likely female and relative-provided, is highly common. Rehabilitation care access is low and inequitable. Our results signal a major need to implement strategies to guarantee the highest standard of health care for people with disabilities.
\end{abstract}

\footnotetext{
> Implications for Rehabilitation

- Major inequality patterns in terms of burden of disability versus access to rehabilitation care were observed: those groups who concentrate more disability reported receiving less rehabilitation care.

- Caregiving is mostly informal and provided by a direct relative, mainly a woman, who resigned to their usual activities in order to help care for the person with disability. As a result, there is a need to develop appropriate support and training for caregivers.

- Access to care services in Peru is low and inequitable, but especially for people with disabilities: they experience greater barriers when accessing healthcare services even in the case of having health insurance.
}

Keywords

Activities of daily living, care, care givers, Peru

History

Received 3 October 2014

Revised 2 March 2015

Accepted 11 May 2015

Published online 28 May 2015

\section{Introduction}

Disability can be defined as a difficulty in functioning at the body, person or societal levels, in one or more life domains, as

Address for correspondence: Antonio Bernabe-Ortiz, MD, MPH, CRONICAS Center of Excellence in Chronic Diseases, Universidad Peruana Cayetano Heredia, Av. Armendariz 497, Miraflores, Lima 18, Peru. E-mail: Antonio.Bernabe@upch.pe experienced by an individual with a health condition in interaction with contextual factors [1,2]. These health conditions can be visible or invisible, temporary or long-term, episodic or degenerating and may or may not be accompanied by pain [3].

Worldwide, the number of years lived with disability (YLD) have remained largely constant over time but rise steadily with age, especially in the last two decades [4]. As a result, understanding the burden of non-fatal health outcomes is critical 
as health systems would need to respond to increasing disability rates.

There is higher disability prevalence among those older, women and low socioeconomic status [3]. The consequences of disability at a personal and family level include dependency and, therefore, the need for caregiver assistance [5], and increased costs associated with health care and rehabilitation services [6]. In developed countries, most caregivers are middle-aged adults who give their own time to care for a parent or spouse with functional limitations [7].

While appropriate therapy is essential for achieving the best rehabilitation outcomes, factors, such as mobility, health status and severity of the disability, can hamper or prevent access to appropriate health services.

In addition, rates of disability can vary according to definition used and country assessed. Few countries have utilized a specific survey to determine the proportion of the population with disability: $7.1 \%$ in Argentina, $7.6 \%$ in Uruguay, $9.0 \%$ in Mexico, $10.3 \%$ in Nicaragua and $12.9 \%$ in Chile [8]. However, information about the burden and extent of disability, dependency and access to disability-specific rehabilitation care in other resource-constrained settings continues being scarce. Therefore, using data of the first nationwide study about disability in Peru, the aims of this study were: (a) to determine the national level prevalence of disability; (b) to explore dependency on caregiver assistance among people with disability and (c) to explore patterns of access to rehabilitation care services, as well as factors that may hinder or promote such access in a resource-constrained setting.

\section{Materials and methods}

\section{Study design and settings}

This cross-sectional study analyzed data from a nationwide population-based survey, the Encuesta Nacional Especializada sobre Discapacidad (Disability National Survey, ENEDIS) [9], conducted between July 2012 and March 2013. The study included data from rural and urban settings in and around several Peruvian cities.

\section{Sampling methods}

For the ENEDIS survey, researchers drew a random sample of participants from 2007 Peruvian census data using a standard probabilistic two-step procedure. In urban areas, the first step involved the random selection of clusters of individual residential blocks or groups of contiguous residential blocks (primary sampling units) for each participating city, proportional to the number of households. Each block comprised an average of 140 households. Then, a census of all households (secondary sampling units) in the selected clusters was conducted by trained interviewers to collect information about household and demographic characteristics. In rural areas, primary sampling units were villages of 500-2000 people and secondary sampling units were households within these villages. All household members, men and women, of any age, and usual residents living at least 6 months in the household were surveyed.

\section{Procedures and questionnaires}

Questionnaires were administered in Spanish by trained fieldworkers. Two different instruments were used according to the phase of the study:

(a) Screening phase: A template was used to collect individuallevel data (sex, age and education level), household location and characteristics including housing type (main material of walls, floor and roof, water and sanitation access, type of fuel used, and assets and services) and six screening questions to evaluate permanent limitations adapted from the recommended short set of questions of the Washington Group on Disability Statistics [10]. Data were recorded for all respondents considered to be usual resident of the randomly selected household. This information was provided by the head of the family or his/her spouse.

(b) Questionnaire for people with disabilities: A detailed questionnaire about limitation characteristics, autonomy and dependency, access to rehabilitation care services, health insurance and access to social programmes, was administered to respondents classified in the screening phase as having a disability. A direct assessment was performed by re-applying the same screening tool to the selected person with disability. Information was provided by the same person with disability or by another family member in the case that the participant was aged $<12$ years or could not respond because of their limitation.

\section{Variables definition}

Disability was defined as any permanent limitation, whether physical, mental, intellectual or sensorial. Specifically, questions addressed whether any of the family members of the enrolled households had any movement limitations, visual impairments, communication difficulties, hearing impairments, difficulties with learning and/or remembering and difficulties with social relationships, through six yes/no questions. Participants who responded "yes" to any of the questions were classified as having a disability.

Dependency was defined as the self-reported need of assistance with activities of daily living, and was assessed by the question: "Does this(these) limitation(s) make you depend on another(other) person(s)?" To confirm dependency, participants were asked to define the kind of activities they receive assistance with; for example, eating and drinking, dressing, undressing or grooming, helping with personal care or moving indoors. Characteristics of caregivers were also recorded.

Access to rehabilitation-specific care was defined as the selfreported access to disability-specific rehabilitation therapy, such as physical therapy, psychological or psychiatric therapy, language therapy, emotional support or occupational therapy. In addition, data about participation in governmental social support programmes (food assistance, educational or occupational programmes) were also collected.

Other variables included in the analysis to characterize the population's profile and potential related factors were: sex, age $(<12,12-19,20-35,36-64$ and 65+ years), educational level (no education, primary, secondary and superior), socioeconomic position (assessed using variables about possession assets, and then combined into a deprivation index, in tertiles) and study area (rural versus urban).

To explore factors associated with access to rehabilitation care, we also looked at data about history of chronic disease (yes/no self-reports about conditions including, among others, diabetes, heart disease, asthma, chronic respiratory conditions, chronic kidney disease) and ownership of (yes/no) and type of health insurance (the Seguro Integral de Salud, supported by the government for vulnerable people; the Social Security, for those in salaried position or voluntarily paying for increased coverage and private health insurance).

\section{Statistical analysis}

For statistical analyses, we used STATA 13 for Windows (STATA Corp., College Station, TX). All estimates were calculated taking into account sample strata, primary sampling units and population 
weights using SVY commands. Appropriate techniques were used for estimating results in subpopulations of interest [11], and projections of estimates by Peru's population size were pursued.

First, population characteristics were described according to the presence of disability. Prevalence of disability, dependency and access to rehabilitation care were estimated, including its $95 \%$ confidence intervals (95\%CIs). Second, sociodemographic variables were assessed as potential factors associated with disability and access to rehabilitation using Pearson's Chi squared test or Fisher's exact test for independent samples. Finally, bivariable and multivariable models were conducted using Poisson regression. Prevalence ratios (PRs) with 95\%CI were reported.

\section{Ethical issues}

The Disability National Survey (ENEDIS) is a publicly available de-identified dataset stored at a national repository [9]; therefore, approval from an Institutional Review Board was not considered mandatory. The dataset used does not provide any information that would have breached participants' confidentiality.

\section{Results}

\section{Burden of disability}

Data from 798308 people were collected during the screening phase of the study; $37524(5.1 \%$; 95\%CI: 4.9-5.2\%) of them were classified as having a disability. For the second phase of the study, the disability-specific survey, inconsistent data were $1.1 \%$; this left a total of 37117 participants included in analysis, with mean age $57.8(\mathrm{SD} \pm 24.1)$ years, and $52.1 \%$ women.

Of participants with disabilities, $41.4 \%$ had one disability, $30.5 \%$ presented two disabilities, $16.6 \%$ had three disabilities and $11.5 \%$ had four or more disabilities. Further detail about participation, rejection, incomplete data and type of disability is shown in Figure 1. Sociodemographic characteristics of the study population are shown in Table 1 .

Projections to Peru's total population yielded a total of 1574000 people with at least one disability. Of them, 650000 had one disability, 480000 with two disabilities, 262000 with three disabilities and 182000 with four or more disabilities. Detailed information about variables associated with disability status is shown in Table 2.

\section{Dependency on caregivers and profile of caregivers}

Among participants with a disability, dependency was selfreported by 14980 (40.5\%; 95\%CI: 39.2-41.9\%). Dependency was more common among women $(p<0.05)$, those with younger age $(p<0.001)$, lower education level $(p<0.001)$, with history of

Table 1. Sociodemographic characteristics of the study population.

\begin{tabular}{|c|c|c|c|c|}
\hline & \multicolumn{2}{|c|}{$\begin{array}{c}\text { People without } \\
\text { disability }(n=760784)\end{array}$} & \multicolumn{2}{|c|}{$\begin{array}{c}\text { People with } \\
\text { disability }(n=37524)\end{array}$} \\
\hline & $N$ & $\%$ & $N$ & $\%$ \\
\hline \multicolumn{5}{|l|}{ Sex } \\
\hline Female & 382860 & $94.8 \%$ & 19456 & $5.2 \%$ \\
\hline Male & 377924 & $95.1 \%$ & 18068 & $4.9 \%$ \\
\hline \multicolumn{5}{|l|}{ Age } \\
\hline$<12$ years & 177805 & $98.6 \%$ & 2431 & $1.4 \%$ \\
\hline $12-19$ years & 123134 & $98.3 \%$ & 2096 & $1.7 \%$ \\
\hline $20-35$ years & 195911 & $98.2 \%$ & 3518 & $1.8 \%$ \\
\hline $36-64$ years & 223605 & $95.1 \%$ & 11316 & $4.9 \%$ \\
\hline $65+$ years & 40329 & $67.1 \%$ & 18163 & $32.9 \%$ \\
\hline \multicolumn{5}{|l|}{ Education level } \\
\hline Superior & 145247 & $97.0 \%$ & 3786 & $3.0 \%$ \\
\hline Secondary & 264207 & $96.8 \%$ & 7662 & $3.2 \%$ \\
\hline Primary & 218903 & $92.8 \%$ & 15376 & $7.2 \%$ \\
\hline No education & 90572 & $89.5 \%$ & 10319 & $10.5 \%$ \\
\hline \multicolumn{5}{|c|}{ Socioeconomic position } \\
\hline Lowest & 252267 & $94.8 \%$ & 13887 & $5.2 \%$ \\
\hline Middle & 254656 & $95.0 \%$ & 12221 & $5.0 \%$ \\
\hline Highest & 253861 & $95.0 \%$ & 11416 & $5.0 \%$ \\
\hline \multicolumn{5}{|l|}{ Study area } \\
\hline Rural & 214991 & $95.9 \%$ & 9118 & $4.1 \%$ \\
\hline Urban & 545793 & $94.6 \%$ & 28406 & $5.4 \%$ \\
\hline
\end{tabular}

Result may not add due to missing values. Percentages were calculated in rows and accounting for sample strata, primary sampling units and population weights.
Figure 1. Flowchart of study participants' enrollment. Respondents may appear in more than one disability group. Disabilities proportions were calculated accounting for sample strata, primary sampling units and population weights.

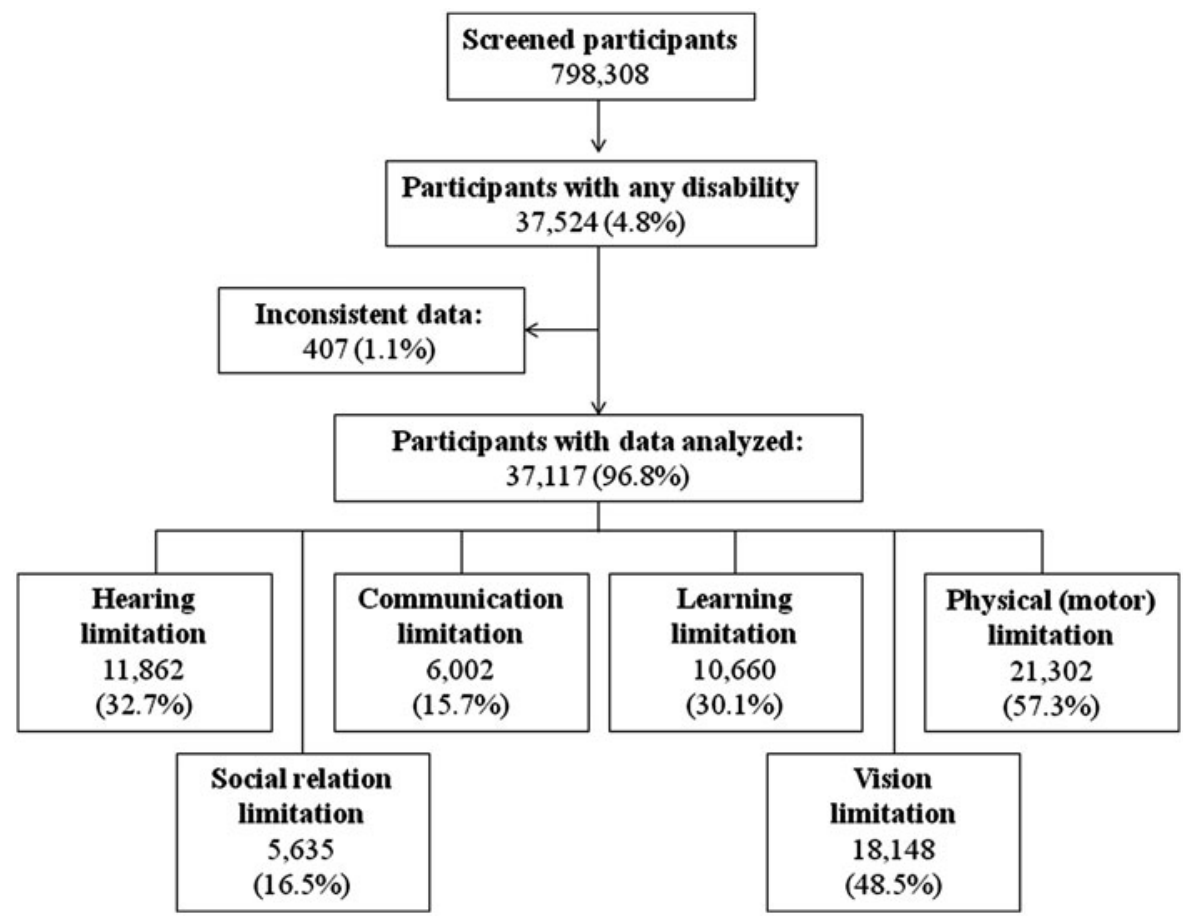


Table 2. Factors associated with disability: bivariate and multivariable models accounting for sample strata, primary sampling units and population weights.

\begin{tabular}{|c|c|c|}
\hline & $\begin{array}{l}\text { Bivariate model } \\
\text { PR }(95 \% \mathrm{CI})\end{array}$ & $\begin{array}{l}\text { Multivariate model } \\
\text { PR }(95 \% \mathrm{CI})^{\mathrm{a}}\end{array}$ \\
\hline \multicolumn{3}{|l|}{ Sex } \\
\hline Female & 1 (Reference) & 1 (Reference) \\
\hline Male & $0.94(0.91-0.96)$ & $1.14(1.11-1.18)$ \\
\hline \multicolumn{3}{|l|}{ Age } \\
\hline$<12$ years & 1 (Reference) & 1 (Reference) \\
\hline $12-19$ years & $1.17(1.08-1.26)$ & 2.07 (1.88-2.29) \\
\hline 20-35 years & $1.22(1.13-1.32)$ & $2.36(2.13-2.61)$ \\
\hline $36-64$ years & 3.41 (3.17-3.67) & $5.55(5.11-6.02)$ \\
\hline $65+$ years & $22.70(20.95-24.60)$ & $26.40(24.42-28.54)$ \\
\hline \multicolumn{3}{|l|}{ Education level } \\
\hline Superior & 1 (Reference) & 1 (Reference) \\
\hline Secondary & $1.06(0.97-1.14)$ & $1.26(1.17-1.35)$ \\
\hline Primary & $2.39(2.14-2.67)$ & $2.35(2.13-2.60)$ \\
\hline No education & $3.49(3.13-3.88)$ & $3.98(3.57-4.44)$ \\
\hline \multicolumn{3}{|c|}{ Socioeconomic position } \\
\hline Lowest & 1 (Reference) & 1 (Reference) \\
\hline Middle & $0.95(0.90-1.01)$ & 1.05 (1.01-1.10) \\
\hline Highest & $0.96(0.89-1.03)$ & $1.08(1.02-1.14)$ \\
\hline \multicolumn{3}{|l|}{ Study area } \\
\hline Rural & 1 (Reference) & 1 (Reference) \\
\hline Urban & $1.31(1.21-1.41)$ & $1.77(1.65-1.90)$ \\
\hline
\end{tabular}

Bold values are significant $(p<0.05)$.

${ }^{\mathrm{a}}$ Factors independently associated with disability.

chronic diseases $(p=0.01)$ and greater number of limitations $(p<0.001)$. Details are shown in Table 3 .

Almost all individuals who reported dependency (94.3\%; 95\%CI: 93.3-95.3\%) identified a family member as the person usually assuming the role of caregiver. Female caregivers were more commonly reported than male caregivers (67.0\%): wives (30.9\% versus $14.6 \%$ of husbands giving care to their partner), daughters $(29.5 \%$ versus $12.8 \%$ of sons $)$ or mothers $(26.1 \%$ versus $6.7 \%$ of fathers), all $p<0.001$.

Almost all (95.9\%) caregivers gave up their usual activities in order to help care for the person with disability. Only $1.9 \%$ of family members were paid for their caregiving duties, and, on average, received PEN 253.7 ( $S D \pm 26.3$ ) Nuevos Soles ( USD \$91, GBP £54) per month. A small proportion of dependent participants, $0.6 \%$ (95\% CI: $0.4-0.8 \%)$, reported having a health professional regularly available to help with daily activities.

\section{Access to rehabilitation care and health insurance}

More than a third of respondents in this survey did not have health insurance (13968 [38.4\%]; 95\%CI: 37.2-39.7\%). Of those who did have health insurance, $29.7 \%$ were enrolled in the Seguro Integral de Salud (offered by the Ministry of Health), $28.6 \%$ in the Social Security and $3.2 \%$ had other health insurances. A total of 4379 respondents (11.7\%; 95\%CI: $10.7-12.8 \%)$ were enrolled in a governmental social programmes at the moment of assessment.

Of all the participants with a disability, only 2881 (10.7\%; 95\%CI: 9.7-11.9\%) reported any access to rehabilitation care services, whereas 4278 (14.5\%: 95\%CI: $12.9-16.2 \%)$ reported that they did not need rehabilitation and were excluded from further analysis. In the final multivariable regression model, factors positively associated with access to rehabilitation services were: higher education level $(p<0.001)$, higher socioeconomic position $(p<0.001)$, urban study area $(p<0.001)$, history of chronic disease $(p<0.001)$, health insurance type $(p<0.001)$ and dependency $(p<0.001)$. On the other hand, older age $(p<0.001)$ was negatively associated with rehabilitation access (Table 4 ).

\section{Discussion}

There are an estimated 1.6 million Peruvians with at least one disability, and around $60 \%$ of these people will have two or more limitations. Approximately $40 \%$ of people with a disability reported dependency on caregiver's assistance, and this responsibility falls largely on a female family member. Only $10 \%$ of people with disabilities reported access to rehabilitation services. All of these main findings, derived from a large nationallyrepresentative survey, are coupled with major inequality patterns in terms of burden of disability versus access to rehabilitation care observed according to age and education level: those groups who concentrate more disability reported receiving less rehabilitation care.

\section{Disability prevalence and associated factors}

In our study, one in 20 participants reported having at least one disability. Information shows that reported prevalence of disability varies significantly between countries: very high in developed countries, i.e. around one in five people in the UK and US [12,13], followed by Chile 12.9\% [14], Mexico $10.7 \%$ [15], Ireland 9.3\% [16] and low in low and middle income countries, such as Kenya $4.6 \%$ [17]. Reasons for these differences might underlay in the approach used to measure disability; for example, the use of specially designed surveys than drawing data from census in developed countries. In addition, other factors, such as more elderly people and higher survival rates for people with disabling conditions in richer countries, and poor health care and unsafe living conditions in developing countries, could explain the wide variation of disability prevalence reported [18].

As in other reports, motor impairments were the most frequent limitation, followed by visual impairment [13,14,16,17]. Compared with the general population, disability was more prevalent among male respondents, older people, those with low education, those with high socioeconomic position and those from urban areas. As expected, an aging population means that more people will present with disabilities, but also as a consequence of increasing survival rates from disease or injury and age-associated disability.

Some conflicting findings in our results deserve some comments, many of them related to the cross-sectional nature of the study. It has been reported that persons with disabilities tend to be concentrated in poorer areas [13]. Our results, however, did show that disability prevalence was lower in rural areas, usually the poorest in Peru, compared to urban settings. In addition, the socioeconomic variables studied yielded opposite findings too. People with a high education level reported lower disability rates; on the other hand, individuals with better socioeconomic position reported greater disability prevalence, perhaps due to survival bias and access-to-care bias. This indicates the challenge of using single socioeconomic indicators to characterize disability profiles in transitioning countries. In Peru, reductions in mortality from childhood and communicable diseases have resulted in higher survival rate and longer life expectancy $[19,20]$. In turn, injuries and non-communicable diseases are more common in urban areas and are two of the biggest causes of disability in urban settings [21,22].

\section{Dependency and caregivers}

Our findings highlight that dependency, understood as the need for care and assistance with the activities of daily life, is frequent among people with disabilities. In more than $95 \%$ of cases, caregiving is done by a direct relative, e.g. a spouse, parent or child, rather than a trained health worker. 
Table 3. Factors associated with dependency: bivariate and multivariable models accounting for sample strata, primary sampling units and population weights.

\begin{tabular}{|c|c|c|c|c|}
\hline & \multicolumn{2}{|c|}{ Dependency } & \multirow{2}{*}{$\begin{array}{l}\text { Bivariate model } \\
\text { PR }(95 \% \mathrm{CI})\end{array}$} & \multirow{2}{*}{$\begin{array}{c}\text { Multivariable mode } \\
\text { PR }(95 \% \mathrm{CI})^{\mathrm{a}}\end{array}$} \\
\hline & No & Yes & & \\
\hline \multicolumn{5}{|l|}{ Sex } \\
\hline Female & $58.0 \%$ & $42.0 \%$ & 1 (Reference) & 1 (Reference) \\
\hline Male & $61.1 \%$ & $38.9 \%$ & $0.93(0.89-0.96)$ & $0.96(0.92-0.99)$ \\
\hline \multicolumn{5}{|l|}{ Age } \\
\hline$<12$ years & $32.9 \%$ & $67.1 \%$ & 1 (Reference) & 1 (Reference) \\
\hline $12-19$ years & $50.2 \%$ & $49.8 \%$ & $0.74(0.69-0.80)$ & $0.85(0.78-0.92)$ \\
\hline $20-35$ years & $56.4 \%$ & $43.6 \%$ & $0.65(0.60-0.70)$ & $0.78(0.73-0.84)$ \\
\hline $36-64$ years & $67.7 \%$ & $32.2 \%$ & $0.48(0.44-0.52)$ & $0.63(0.57-0.68)$ \\
\hline $65+$ years & $59.4 \%$ & $40.6 \%$ & $0.60(0.57-0.65)$ & $0.65(0.61-0.70)$ \\
\hline \multicolumn{5}{|l|}{ Education level } \\
\hline No education & $44.5 \%$ & $55.5 \%$ & 1 (Reference) & 1 (Reference) \\
\hline Primary & $61.9 \%$ & $38.1 \%$ & $0.69(0.66-0.72)$ & $0.78(0.74-0.81)$ \\
\hline Secondary & $67.9 \%$ & $32.1 \%$ & $0.58(0.54-0.62)$ & $0.71(0.66-0.76)$ \\
\hline Superior & $70.0 \%$ & $30.0 \%$ & $0.54(0.49-0.60)$ & $0.69(0.62-0.765)$ \\
\hline \multicolumn{5}{|c|}{ Socioeconomic position } \\
\hline Lowest & $57.8 \%$ & $42.2 \%$ & 1 (Reference) & 1 (Reference) \\
\hline Middle & $59.8 \%$ & $40.2 \%$ & $0.95(0.89-1.01)$ & $1.03(0.97-1.09)$ \\
\hline Highest & $60.5 \%$ & $39.5 \%$ & $0.94(0.87-1.00)$ & $1.07(0.99-1.15)$ \\
\hline \multicolumn{5}{|l|}{ Study area } \\
\hline Rural & $57.0 \%$ & $43.0 \%$ & 1 (Reference) & 1 (Reference) \\
\hline Urban & $60.2 \%$ & $39.8 \%$ & $0.93(0.86-0.99)$ & $0.97(0.90-1.05)$ \\
\hline \multicolumn{5}{|c|}{ History of chronic disease } \\
\hline No & $60.4 \%$ & $39.6 \%$ & 1 (Reference) & 1 (Reference) \\
\hline Yes & $58.1 \%$ & $41.9 \%$ & $1.06(1.00-1.11)$ & $1.07(1.01-1.12)$ \\
\hline \multicolumn{5}{|c|}{ Number of limitations } \\
\hline 1 & $71.0 \%$ & $29.0 \%$ & 1 (Reference) & 1 (Reference) \\
\hline 2 & $61.8 \%$ & $38.2 \%$ & $1.31(1.25-1.39)$ & $1.28(1.21-1.35)$ \\
\hline 3 & $47.6 \%$ & $52.4 \%$ & $1.80(1.68-1.94)$ & $1.69(1.58-1.82)$ \\
\hline $4+$ & $29.1 \%$ & $70.9 \%$ & $2.44(2.30-2.59)$ & $2.22(2.08-2.37)$ \\
\hline
\end{tabular}

Bold values were significant $(p<0.05)$.

${ }^{\mathrm{a}}$ Adjusted for all the listed variables.

There are two main findings related to dependency that could be used to plan and implement potential strategies to address challenges for persons living with disabilities. First, the burden on women and girls caring for disabled relatives is disproportionately large: almost two thirds of caregivers are female [23,24]. Second, the rate of informal caregiving, that is, when a paid or unpaid nonprofessional person rather than a trained health worker provides care [25], is enormously high, more than $95 \%$.

Given that these profiles, roles and tasks are conducted entirely separately from the market economy, and at the same time they are socially and politically invisible, its economic and social value is not generally acknowledged [6]. From a health point of view, poor health and even higher rates of mortality have been reported in the informal caregiver population $[7,26]$. Although caring for a family member can be gratifying for some, to certain extent and for certain period of time, it is also clear that caring responsibilities may affect the physical and mental health of caregivers, expressed in terms of stress, exhaustion, family destabilization and impoverishment [27]. In this sense, population-based estimates can provide a solid basis to plan long-term support, not only directed at individuals but also for the development of support networks, and appropriate infrastructure, adequate training and equipment for both caregivers and the person with a disability [6].

\section{Access to rehabilitation care and associated factors}

A person with a disability is at higher risk for health comorbidities and complications, and they also have higher demands for use of disability-specific rehabilitation care $[28,29]$. In this paper, we focused only on rehabilitation therapies required for a disability. Excluding those who self-reported no need for rehabilitation services, we found that approximately one in 10 people with disabilities reported having access to some kind of rehabilitation therapy. A previous study in Chile found that $6.5 \%$ of people with disabilities had received rehabilitation services in the previous year [14].

Among factors independently associated with access to rehabilitation care services, those with higher education and higher socioeconomic position had more access to care as previously reported [30,31]. This finding clearly reflects two major inequality patterns of burden of disability versus access to rehabilitation care: older age groups had higher disability burden yet lower chances of access to rehabilitation care, as well as those with lower education and lower socioeconomic position. Conversely, the higher the education level, the lesser the overall disability burden but also the higher chances of reporting receiving rehabilitation care. In addition, people living in rural areas reported lower rates of access to rehabilitation services. The latter could be related to barriers at the health system level, no health insurance, a lack of specialized health services or specialists in rural areas, as well as geographical barriers that create difficulties for transportation to care.

The presence of a chronic disease was positively associated with access to rehabilitation: the presence of such conditions may significantly increase the likelihood of another physical as well as mental health condition $[32,33]$, and thus increase the probability to look for healthcare services. The increase in non-communicable diseases, including diabetes, cardiovascular diseases, cancer, etc. is responsible for $66.5 \%$ of all years lived with disability in 
Table 4. Factors associated with access to rehabilitation care: bivariable and multivariable models accounting for sample strata, primary sampling units and population weights.

\begin{tabular}{|c|c|c|c|c|}
\hline & \multicolumn{2}{|c|}{ Access to health care } & \multirow{2}{*}{$\begin{array}{c}\text { Bivariate model } \\
\text { PR }(95 \% \mathrm{CI})\end{array}$} & \multirow{2}{*}{$\begin{array}{c}\text { Multivariable mode } \\
\text { PR }(95 \% \mathrm{CI})^{\mathrm{a}}\end{array}$} \\
\hline & No & Yes & & \\
\hline \multicolumn{5}{|l|}{ Sex } \\
\hline Female & $87.7 \%$ & $12.2 \%$ & 1 (Reference) & 1 (Reference) \\
\hline Male & $87.2 \%$ & $12.8 \%$ & $1.05(0.96-1.14)$ & $0.94(0.86-1.02)$ \\
\hline \multicolumn{5}{|l|}{ Age } \\
\hline$<12$ years & $70.6 \%$ & $29.4 \%$ & 1 (Reference) & 1 (Reference) \\
\hline $12-19$ years & $80.8 \%$ & $19.2 \%$ & $0.65(0.54-0.78)$ & $0.63(0.51-0.77)$ \\
\hline $20-35$ years & $86.6 \%$ & $13.4 \%$ & $0.46(0.38-0.55)$ & $0.44(0.35-0.55)$ \\
\hline $36-64$ years & $86.1 \%$ & $13.9 \%$ & $0.47(0.41-0.55)$ & $0.38(0.31-0.46)$ \\
\hline $65+$ years & $91.3 \%$ & $8.7 \%$ & $0.30(0.25-0.34)$ & $0.22(0.18-0.26)$ \\
\hline \multicolumn{5}{|l|}{ Education level } \\
\hline No education & $90.8 \%$ & $9.2 \%$ & 1 (Reference) & 1 (Reference) \\
\hline Primary & $90.1 \%$ & $9.9 \%$ & $1.07(0.92-1.26)$ & $1.22(1.05-1.41)$ \\
\hline Secondary & $83.4 \%$ & $16.6 \%$ & $1.81(1.56-2.11)$ & $1.66(1.41-1.95)$ \\
\hline Superior & $80.3 \%$ & $19.7 \%$ & $2.15(1.74-2.65)$ & $1.64(1.30-2.06)$ \\
\hline \multicolumn{5}{|l|}{ Socioeconomic position } \\
\hline Lowest & $96.1 \%$ & $3.8 \%$ & 1 (Reference) & 1 (Reference) \\
\hline Middle & $87.5 \%$ & $12.5 \%$ & $3.24(2.70-3.88)$ & $1.77(1.46-2.14)$ \\
\hline Highest & $80.8 \%$ & $19.2 \%$ & $4.96(4.07-6.05)$ & $2.21(1.80-2.71)$ \\
\hline \multicolumn{5}{|l|}{ Study area } \\
\hline Rural & $97.1 \%$ & $2.9 \%$ & 1 (Reference) & 1 (Reference) \\
\hline Urban & $84.6 \%$ & $15.4 \%$ & $5.36(4.29-6.70)$ & $2.56(2.00-3.26)$ \\
\hline \multicolumn{5}{|l|}{ History of chronic disease } \\
\hline No & $88.8 \%$ & $11.2 \%$ & 1 (Reference) & 1 (Reference) \\
\hline Yes & $85.6 \%$ & $14.4 \%$ & $1.28(1.14-1.44)$ & $1.13(1.04-1.30)$ \\
\hline \multicolumn{5}{|l|}{ Health insurance } \\
\hline No & $90.9 \%$ & $9.1 \%$ & 1 (Reference) & 1 (Reference) \\
\hline Seguro Integral de Salud & $92.0 \%$ & $8.0 \%$ & $0.87(0.72-1.05)$ & $1.08(0.90-1.29)$ \\
\hline Social Security & $79.4 \%$ & $20.6 \%$ & $2.25(1.97-2.56)$ & $1.83(1.58-2.12)$ \\
\hline Other (private, etc.) & $73.1 \%$ & $26.9 \%$ & $2.94(2.32-3.73)$ & $2.18(1.68-2.84)$ \\
\hline \multicolumn{5}{|l|}{ Dependency } \\
\hline No & $90.8 \%$ & $9.2 \%$ & 1 (Reference) & 1 (Reference) \\
\hline Yes & $83.2 \%$ & $16.8 \%$ & $1.83(1.64-2.04)$ & 1.78 (1.61-1.98) \\
\hline
\end{tabular}

low- and middle-income countries [34], and therefore, will have a significant effect on health-system infrastructure and organization $[35,36]$. Finally, our results regarding health insurance are comparable with previous findings showing that people with disabilities experience greater barriers when accessing health services [37], and uninsured individuals with disabilities have greater problems accessing healthcare services than do uninsured people without disabilities [38]. Therefore, access to rehabilitation care services in Peru, as perhaps in other low and middle income countries, is low and inequitable.

\section{Strengths and limitations}

This is the first nationwide population-based study assessing the prevalence of disability and rates of access to services in Peru. The main strengths of our study include the sample size, the multistage techniques used for determining estimates and projections, the inclusion of participants from all ages, as well as the wide coverage including urban and rural settings. However, some limitations deserve consideration. First, the cross-sectional study design, while valuable for prevalence estimation, can only determine association and not causality, which can be important for a more detailed ascertainment of care and service needs. Second, data of the duration, cause and severity of the disability were not available for this analysis, hence limiting a more fine assessment of the burden of disability. Third, information on dependency, caregiving and access to rehabilitation care was selfreported as was the history of chronic diseases. A large proportion of respondents may not be aware that they have non-communicable conditions, especially in settings, like Peru, where primary health care and diagnostic services are not always available [39]. Similarly, in the case of dependency and access to rehabilitation care, social desirability and information bias might emerge. For example, $18.2 \%$ of the participants that reported not to need rehabilitation services were dependent, whereas it was the case for $41.2 \%$ of those not receiving rehabilitation services and $59.2 \%$ of those who reported received it. As a result, given the nature of the condition of disability, we expect these not to be major biases.

Finally, all limitations (physical, visual, hearing, communication, learning and those surrounding social relation) were grouped, which unfortunately did not allow for comparisons between different types of limitation.

\section{Conclusions}

Almost 1.6 million Peruvians have at least one disability, and 40\% of them require assistance with daily activities. Informal caregiving is very common, and access to rehabilitation should be a priority. The heavy burden of disability and the largely socially and politically invisible role of caregiving, together with an economic and societal value that is not generally acknowledged, indicate the need for several strategies to guarantee appropriate disability statistics over time, to support families as caregivers providers, and to ensure the highest standard of health for people with disabilities. 


\section{Acknowledgements}

Data used in this publication come from the Encuesta Nacional Especializada sobre Discapacidad (Disability National Survey, ENEDIS). We would like to thank and recognize the work of staff of the Instituto Nacional de Estadística e Informática (INEI), in Lima, Peru, for performing this population-based survey and make the data available.

\section{Declaration of interest}

The authors declare no conflict of interests. AB-O, FDC and JJM are supported by CRONICAS Center of Excellence in Chronic Diseases at Universidad Peruana Cayetano Heredia, in Lima, Peru. AB-O is supported by a Wellcome Trust Research Training Fellowship in Public Health and Tropical Medicine (Grant number: 103994/Z/14/Z). AV is supported by Sociedad y Discapacidad - SODIS, Lima Peru.

\section{References}

1. United Nations Enable. Eight session on the ad hoc committee on a comprehensive and integral international convention on protection and promotion of the rights and dignity of persons with disabilities. 2006. Available from: http://www.un.org/esa/socdev/enable/rights/ ahc8.htm [last accessed 2 Oct 2014].

2. Leonardi M, Bickenbach J, Ustun TB, et al. The definition of disability: what is in a name? Lancet 2006;368:1219-21.

3. World Health Organization. World report on disability. Geneva, Switzerland: WHO; 2011.

4. Vos T, Flaxman AD, Naghavi M, et al. Years lived with disability (YLDs) for 1160 sequelae of 289 diseases and injuries 1990-2010: a systematic analysis for the Global Burden of Disease Study 2010. Lancet 2013;380:2163-96.

5. Boerner K, Schulz R. Caregiving, bereavement and complicated grief. Bereave Care 2009;28:10-13.

6. Arno PS, Levine C, Memmott MM. The economic value of informal caregiving. Health Aff (Millwood) 1999;18:182-8.

7. Schulz R, Beach SR. Caregiving as a risk factor for mortality: the Caregiver Health Effects Study. JAMA 1999;282:2215-19.

8. Organizacion Panamericana de la Salud. Aplicacion de la Clasificacion International del Funcionamiento, de la Discapacidad y de la Salud en estudios de prevalencia de discapacidad en las Americas. Washington DC: OPS; 2012.

9. Instituto Nacional de Estadística e Informática. Lima, Perú: INEI; 2012. Available from: http://iinei.inei.gob.pe/microdatos/ [last accessed 10 Nov 2014].

10. Washington Group on Disability Statistics. Understanding and interpreting disability as measured using the Washington Group short set of questions. Atlanta, US: Centers for Disease Control and Prevention; 2009.

11. West BT, Berglund P, Heeringa SG. A closer examination of subpopulation analysis of complex-sample survey data. Stata J 2008; 8:520-31.

12. Brault MW. Americans with disabilities: 2010. Household economic studies. US Department of Commerce: Economics and Statistics Administration. Washington, DC: US Census Bureau; 2012.

13. Papworth Trust. Disability in the United Kingdom 2012: facts and figures. Cambridge, UK: Papworth Trust; 2012.

14. Fondo Nacional de la Discapacidad. Primer Estudio Nacional para Discapacidad en Chile. Santiago, Chile: Fondo Nacional de la Discapacidad; 2004.

15. Lozano R, Soliz P. Measurement of disability in Mexico: a different approach. Mexico City, Mexico: CEMECE, Ministry of Health; 2005.
16. Central Statistics Office. National disability survey 2006: fists results. Dublin, Ireland: Central Statistics Office; 2008.

17. National Coordinating Agency for Population and Development. Kenya national survey for persons with disability. Nairobi, Kenya: National Coordinating Agency for Population and Development; 2008.

18. Mont D. Measuring disability prevalence. Washington DC: The World Bank; 2007.

19. Huicho L, Trelles M, Gonzales F, et al. Mortality profiles in a country facing epidemiological transition: an analysis of registered data. BMC Public Health 2009;9:47.

20. Velasquez A. La carga de enfermedad y lesiones en el Peru. Lima, Peru: Ministerio de Salud; 2008.

21. Murray CJ, Ezzati M, Flaxman AD, et al. GBD 2010: design, definitions, and metrics. Lancet 2012;380:2063-6.

22. Murray CJ, Vos T, Lozano R, et al. Disability-adjusted life years (DALYs) for 291 diseases and injuries in 21 regions, 1990-2010: a systematic analysis for the Global Burden of Disease Study 2010. Lancet 2012;380:2197-223.

23. Dahlberg L, Demack S, Bambra C. Age and gender of informal carers: a population-based study in the UK. Health Soc Care Community 2007;15:439-45.

24. Schofield HL, Herrman HE, Bloch S, et al. A profile of Australian family caregivers: diversity of roles and circumstances. Aust N Z J Public Health 1997;21:59-66.

25. Norgard TM, Rodgers WL. Patterns of in-home care among elderly black and white Americans. J Gerontol B Psychol Sci Soc Sci 1997; 52 Spec No:93-101.

26. Legg L, Weir CJ, Langhorne $\mathrm{P}$, et al. Is informal caregiving independently associated with poor health? A population-based study. J Epidemiol Community Health 2013;67:95-7.

27. Trivedi R, Beaver K, Bouldin E, et al. Characteristics and well-being of informal caregivers: results from a nationally-representative US survey. Chronic Illn 2013;10:167-79.

28. Barry LC, Soulos PR, Murphy TE, et al. Association between indicators of disability burden and subsequent depression among older persons. J Gerontol A Biol Sci Med Sci 2013;68:286-92.

29. Smith AK, Walter LC, Miao Y, et al. Disability during the last two years of life. JAMA Intern Med 2013;173:1506-13.

30. Amaral FL, Motta MH, da Silva LP, Alves SB. Factors associated with difficulty of access of the elderly with disabilities to the health services. Cien Saude Colet 2012;17:2991-3001.

31. Pereira GN, Bastos GA, Del Duca GF, Bos AJ. Socioeconomic and demographic indicators associated with functional disability in the elderly. Cad Saude Publica 2012;28:2035-42.

32. Croft P, Dunn KM, Von Korff M. Chronic pain syndromes: you can't have one without another. Pain 2007;131:237-8.

33. Gureje O, Von Korff M, Kola L, et al. The relation between multiple pains and mental disorders: results from the World Mental Health Surveys. Pain 2008;135:82-91.

34. World Health Organization. The global burden of disease: 2004 update. Geneva, Switzerland: WHO; 2008.

35. Engelgau MM, Geiss LS, Saaddine JB, et al. The evolving diabetes burden in the United States. Ann Intern Med 2004;140:945-50.

36. World Health Organization. Preventing chronic diseases: a vital investment. WHO global report. Geneva, Switzerland: WHO; 2005.

37. Wang TF, Shi L, Nie X, Zhu J. Race/ethnicity, insurance, income and access to care: the influence of health status. Int J Equity Health 2013;12:29.

38. Iezzoni LI, Frakt AB, Pizer SD. Uninsured persons with disability confront substantial barriers to health care services. Disabil Health J 2011;4:238-44.

39. Lerner AG, Bernabe-Ortiz A, Gilman RH, et al. The "rule of halves" does not apply in Peru: awareness, treatment, and control of hypertension and diabetes in rural, urban, and rural-to-urban migrants. Crit Pathw Cardiol 2013;12:53-8. 